\title{
Dynamics of Behavioural Expertise under COVID-19
}

Joram Feitsma, Utrecht University

Mark Whitehead, Aberystwyth University

*working paper*

Many government responses to the coronavirus-pandemic have been marked by attempts at expertization and scientization. Particularly, politico-epistemological authority is being given to the behavioural science community consulting government. This article critically scrutinizes this most recent wave of behavioural expertization. Taking developments in the UK and the Netherlands as our case-studies, we shed light on the disparate ways in which behavioural expertise is being (re)shaped during COVID-19. Some of these ways point at processes of behavioural expertise 'drift', in which the applicability and robustness of this knowledge source gets overstated. Other ways instead point at processes of behavioural expertise 'thrift' or 'shift', where the knowledge is used only minimally or taken in wholly new and norm-breaking directions. Doing so, we seek to demonstrate the importance of institutional context in understanding how behavioural expertise is currently shaping public policy: underpinning institutional configurations determine whether the expertise is gauged and applied effectively. 


\section{Introduction: Behavioural expertization during COVID-19}

An important study theme within the policy sciences deals with the changing relationship between the domains of science and policymaking. While this relationship has long been a topic of scientific scrutiny, widely differing accounts are still circulating in the current debate, from those that foresee extreme 'scientization' (Christensen 2018), 'technocratization' (Esmark 2020), 'expertization' (Holst 2012) and related epistocratic forms of governing, to others that perceive policy to be increasingly 'fact-free' and 'post-truth' (McIntyre 2018). In the current context of the COVID-19 crisis it would seem that the expertocratic, scientistic approach has become a, generally, favoured, route. Worldwide, crisis responses have been characterised by a strong tendency towards strategies of depoliticization and scientization, delegating decisionmaking authority to scientific experts. The dominant governing mantra was one of 'following the science'. Close collaborations were formed between public leaders and scientists from different disciplinary cadres - from epidemiologists and virologists, to data scientists and behavioural experts. Ongoing appeals were made to the importance of relying on scientific knowledge and trustable facts, with at one point Dutch premier Mark Rutte labelling the advice of the Outbreak Management Team (the cabinet's main expert advisory committee) as 'holy'.

Within the general push towards scientization, the upcoming field of Behavioural Public Policy (BPP) expertise has appeared to play a leading role (next to of course the confines of virology, epidemiology and medical care). The field of Behavioural Public Policy (hereafter BBP) refers to emerging, and increasingly formalised, interactions between the behavioural sciences (particularly behavioural psychology and behavioural economics) and public policy-making. This field is marked by a particular sensitivity towards the irrational, habitual, and subconscious drivers of human decision-making and a rejection of idealised accounts of homo economicus (see Whitehead et al, 2017). It was not long after the most acute crisis struck that behavioural experts in academia, government and beyond claimed their space in scientific and political debates with an appeal to the urgency and relevance of using behavioural insights to address the pandemic. Inside academia, scientists soon produced new literature overviews, synthesizing existing knowledge about the effects of all sorts of pandemic-related behavioural interventions (e.g. Lunn et al. 2020). Within policy circles, renowned behavioural scientists became part of national and international crisis response teams and were consulted at key decision-making events. In the case of the UK, for instance, BPP protagonist and Director of the UK government's Behavioural Insights Team David Halpern acted as member of the Scientific Advisory Group for Emergencies (SAGE) (the UK's main advisory committee of experts), 
facilitating a context in which behavioural science could come to play a vital role in the initial national crisis response. Beyond the consultation of particular BPP individuals, the institutional landscape has seen the rise of new specialised networks and units at the policy-science interface dedicated to understanding and tackling the pandemic. In the Netherlands, for instance, a Corona Behaviour Unit [Corona Gedragsunit] was launched in April 2020. The unit was positioned within the National Institute for Public Health and the Environment (RIVM), and was designated to collect and bundle knowledge at the interface of behaviour, psychology and health in order to inform and support government policy and communication (RIVM 2020).

While the continuing popularity and institutionalization of BPP undoubtedly suggests that it has proven highly valuable for many policy issues including COVID-19, we deem it important to also critically scrutinise this most recent wave of behavioural scientization. Perhaps especially as BPP is extending its influence, it is necessary to foster awareness of the limits, uncertainties and risks that are inherent to using behavioural insights for policy purposes. Indeed, beyond a rise in popularity there has also been an increase in a distinct type of criticism, most notably visible in the UK, arguing that the take-up of behavioural science has been rather ill-informed and hubristic. In this article we understand this specific criticism as behavioural expertise drift, which occurs when experts transcend their knowledge domain or overstate the robustness of their knowledge. Taking the national crisis responses, and their institutional underpinnings, in the UK and the Netherlands as our case-studies, we seek to trace back the role and influence of BPP during the COVID-19 crisis. We argue that in the UK, BPP was highly influential and positioned at the heart of decision-making but also susceptible to instances of expertise drift, exemplified by the contestation surrounding the notion of 'behavioural fatigue'. BPP appeared to play a different role in the Netherlands, where it was less publicly politicised, exercised influence from a more peripheral position, and revealed a seemingly minimised if not altered approach towards BPP. In this article, we attempt to capture these diverging processes of expertise use by introducing the trichotomy of expertise drift, thrift and shift. Crucially, we claim that while these terms provide us with fresh perspectives on the nature of science-policy interface we claim that their activation cannot be explained on the basis on the nature of the science and expertise they embody. We argue that expertise drift, thrift and shift are critically shaped by the institutional contexts within which science-policy interactions occur. 
This article hopes to contribute to scholarly debates in a few ways. On a general level, we seek to add to the fine-grained empirical (and comparative) analysis of contemporary science-policy interaction (e.g. Strassheim 2017; Fischer 1990; Wesselink et al. 2013). Our scrutiny of sciencepolicy dynamics during COVID-19 has direct links to the literatures on depoliticization (e.g. Flinders \& Buller 2006), technocratization (e.g. Esmark 2020) and scientization (Saretzki 2015). We have also sought to connect our analysis to literatures further removed from orthodox policy debates, most notably those on expertise drift and transgressive competence (Nowotny 2000). We centre our analysis around this idea of drift and transgression of expertise, and argue for an expansion of the conceptual vocabulary having observed occurrences of what might be called expertise 'thrift' and 'shift'. More specifically, we seek to add to existing efforts at empirically tracing and critically analysing BPP both before (Ewert 2020; Mulderrig 2018; Strassheim \& Beck 2019) and during the COVID-19 pandemic (Sibony 2020; Pierre 2020).

BPP has been highly popular and presented as the latest hallmark of evidence-based policy (e.g. John 2018; Halpern 2015), but there has also been a more critical camp challenging the (implicit) politics, ethics and epistemics behind this trend (e.g. Leggett 2014; Mulderrig 2018). In line with these aspirations, we hope to lay bare the ultimately more open-ended, contextsensitive role of behavioural science during COVID-19: used competently it produces unique value for policy but when misapplied the value for policy is minimal if not negative. We explore this open-endedness through adopting a distinct institutional (or structural/contextual) lens (e.g. see Pierre 2020 for a contextualized account of BPP in Sweden, and Capano et al. 2020 for a broader contextualized analysis of divergent COVID-19 policy styles across the globe), looking at how specific institutional landscapes or organizational structures may either prevent or facilitate processes of misapplication and drift of expertise.

In what follows, we will first sketch our institutional lens from which to assess the role and influence of BPP during COVID-19. Then we present two case-studies of BPP's role in the national crisis response formulation, one in the UK, the other in the Netherlands. The discussion links the observations back to the theory on expertise drift and introduces the idea of expertise 'thrift' and 'shift'. It ends with a reflection on what makes up an 'expertise-savvy' institutional context that facilitates competent uses of expertise.

\section{Expertise in institutional context}

In the wake of BPP's growing impact on the response of various nations to COVID-19, Susan Michie, a behavioural science advisor to the UK government argued that ' $[\mathrm{w}] \mathrm{e}$ need to study 
the extent to which behavioural science has been applied in different countries and with what effect' (House of Lords 2020). This article can be seen as a response to this call for comparative studies of BPP in response to the current pandemic. In our comparison of the respective use of behavioural insights in the Netherlands and UK, however, we are not as much concerned with particular behaviourally-informed interventions and their effects as we are with broader questions of expertise they reflect. Critical analysis of the operation of scientific expertise within public policy takes various forms. There are analyses which are concerned with the power dynamics which surround claims to expertise (Collins and Evans, 2008; Epstein, 1996; Fischer, 2009; 1990). Related work also considers the impacts that expertise has on the processes of democracy and political contestation (Swyngedouw, 2006; Whitehead et al, 2019) and more specific questions of advisory practices (Stilgoe, 2016). In the analysis we present here our concern is more specific and relates to the nature of the institutional interfaces which facilitate science-policy interactions. Concerns have been raised about the (bounded) interdisciplinary form of much BPP (Feitsma \& Whitehead, 2020), and the dominant position that has been given to certain branches of the behavioural sciences within policy infrastructures (Whitehead et al, 2017). We claim that the COVID-19 crisis provides a context within which it becomes possible to see more clearly the influence of institutional context in shaping the effects that behavioural expertise is able to have on public policy.

According to Nowotny (2000) it is critical to position claims to expertise within the contexts in which they emerge. These contexts may be interpersonal, cultural, institutional, or historical, or indeed various combinations of these. For Nowotny, understanding these contexts is critical to beginning to understand the ways in which claims to expertise exclude other competing claims to knowledge (from 'non-experts' or competing scientific paradigms). In the context of these necessary exclusions, Nowotny claims that expertise is never truly scientific. The call for expertise inevitably means that the expert becomes employed in the service of politics. For Nowotny, the demands of the political inevitably compromise the scientific. He is primarily interested in how expertise transforms science. We are interested, however, in the ways in which institutional contexts influence the forms of behavioural expertise that have informed government responses to COVID-19. And, critically, how these insights may inform future interfaces between public policy and the behavioural sciences.

We use the term institutional context in this paper to refer to something more than just the power of formalised advisory institutions. Although we include named expert panels, 
committees, and units within our analysis of institutions, we also understand institutions in more informal ways. Informal institutional practices pertain as much to how organizations interact (or disengage), produce implicit customs, and share (often unwritten) understandings (see Coulson and Ferrario, 2007). Understood in these terms, institutional context is not only about the impact that individual organizations/unit/committees have on events, but is also about the ways in which institutions coalesce, establish informal hierarchies, and intuitive codes of conduct. In geographical literature this forms of institutional sensibility is often referred to as institutional thickness (ibid). Such a perspective does, of course, also build on a wellestablished tradition of institutional analysis within the study of public policy, administration, and expertise (Jasanoff, 2004). Related works draws attention to the formal and informal ways in which established and emerging institutional systems of working shape the flow of expertise and influence and shape subsequent institutional forms and practices. Ultimately, what an institutional perspectives offers is an insights into how scientific expertise is not only shaped by overt political interventions, but more subtle and often intangible organizational cultures and histories. The call to expertise may reshape science, but this reshaping process is determined by the institutional forms that expertise is called-up to express itself within.

Our analysis focuses on the role of BPP in the early phases of the COVID-19 crisis. In exploring the flow of expertise during this period we consider the degree to which behavioural expertise drifted into areas of limited competence. Expertise drift has been described by Nowotny (2000) as a form of transgressive competence where available experts make judgements on issues beyond the limits of their designated expertise. While we are interested in expertise drift, our analysis (particularly in the context of the UK) seeks to complicate how we might understand the nature of this transgressive competence and the institutional processes which facilitate it. In addition to developing new perspectives on the notion of expertise drift, in this article we introduce the allied concepts of expertise shift and thrift. The processes of expertise shift and thrift are evident in the Dutch case study and offer a vocabulary to understand how responses to COVID-19 have resulted in flows of expertise that move in the opposite direction to the forms of transgressive competence identified by Nowotny. We note how this more humble approach to expertise serves to militate against certain forms of transgressive competence, but is in no way unproblematic in itself.

We now zoom in on two case-studies of sites in which behavioural science has been informing the government response to COVID-19. Pinpointing the role of BPP in different national 
contexts helps to see the influence of institutional context on processes of expertise use. Our analysis relies on the document study of policy reports, committee minutes, media articles, peer-reviewed articles, and other relevant documents pertaining to BPP during COVID-19. Documents were gathered during the period of January to October 2020, focusing on developments (and their institutional underpinnings) in the UK and the Netherlands. Throughout the process of headwork, data gathering and textwork we had different analytical objects in mind: the UK case-study traces the use of a specific concept, while the Dutch casestudy traces the activities of a specific government unit. Both however share a focus on institutional structures and tell something about how expertise gets used within, due to and by its institutional context. We this employed a form of purposive sampling in the evidence that we have gathered as part of this paper. Rather than focusing on the broad sweep of BPP influence on COVID-19 policy, we focused on particular processes that surrounded the mobilisation of a term (in the UK) and a Unit (in the Netherlands). While we believe our we have focused on an important behavioural term and unit, our analysis has been designed to offer a detailed analysis the particularities of BBP expertise than a more complete policy picture. The analysis loosely builds upon previous research projects studying related matters including uses of information technology (Whitehead 2020), mechanisms of depoliticization (Feitsma 2020) and strategies of crisis management (Swinkels \& Feitsma 2020) during COVID-19.

\section{BPP during COVID-19 in the UK: the issue of behavioural fatigue}

The rise to public prominence of the behavioural sciences in relation to COVID-19 policy in the UK is connected, primarily, to one concept - behavioural fatigue. Positioned as both a 'common sense' notion and 'behavioural science' theory, behavioural fatigue first came to prominence when it was alluded to by the UK's Chief Medical Officer, Chris Whitty, in March 2020. In the context of the timing of a national lockdown, he stated that: 'There is a risk that if we go too early people will understandably get fatigued and it will be difficult to sustain this over time' (Chris Whitty 2020, quoted in Mahase, 2020). At this point you will notice that Whitty refers only to fatigue. Precisely when this term transformed into behavioural fatigue is unclear. What is certain is that the addition of this behavioural prefix gave the term a semblance of scientific credibility and associated it directly with the behavioural sciences.

The concept of behavioural fatigue rose to prominence because it was one of the main public explanations that was given in the UK to justify the decision to delay lock-down. While there were, undoubtedly, other reasons that informed politicians' decision to delay lockdown, it is 
now argued that this action was, most likely, one of the key factors that resulted in the UK recording more COVID-19 deaths than many of its European neighbours (Abbasi, 2020). What is interesting about the notion of behavioural fatigue is that despite its close association with the behavioural sciences, it is a concept that most behavioural scientists in the UK quickly distanced themselves from. Thus, in this section we do not use behavioural fatigue to tell a straightforward story of how, and with what effects, behavioural science informed public policy in the UK. Instead, we use the concept as a context through which to explore, and problematise, the notion of behavioural expertise drift and associated forms of transgressive competence that are linked with behavioural science. We claim that the apparent influence of this concept exposes the lasting institutional impacts of certain branches of the behavioural sciences in shaping how government understands of the human subject and reveals a narrowness in the science-policy interface in the UK.

\section{The behavioural science-public policy interface in the UK}

Before discussing the nature and impact of the concept of behavioural fatigue, it is important to understand the formal institutional interfaces that exists between the behavioural sciences and COVID-19 policy making in the UK. The behavioural sciences have informed pandemic response in the UK via two main routes. The first is the Independent Pandemic Influenza Group on Behaviours (hereafter SPI-B). According to the UK Government SPI-B '[...] provides behavioural science advice aimed at anticipating and helping people adhere to interventions that are recommended by medical or epidemiological experts' (SPI-B 2020). This group of independent academic experts draws on representation from the fields of behavioural science, health and social psychology, anthropologists, and historians ${ }^{1}$. The scientists on SPI-B provide expert advice to the Scientific Advisory Group for Emergencies (SAGE), which in turn advises government ministers and policy officials. ${ }^{2}$

The second route for behavioural expert influence is through the Behavioural Insights Team (BIT). The BIT was established under the David Cameron Administration in order to enable the latest insights within behavioural sciences to inform the design and implementation of public policy in the UK (See Halpern, 2015; Jones et al 2013; and Whitehead et al 2017). The

\footnotetext{
${ }^{1}$ SPI-B's membership itself draws an important line of distinction between behavioural science (as a specific disciplinary space of inquiry), and the broader fields associated with the sciences which study human behaviour.

${ }^{2}$ SPI-B previously advised the UK government on the behavioural implications of the Ebola outbreak in west Africa. SPI-B has its origins in 2009, when SAGE formed a Scientific Pandemic Influenza group on Behaviour and Communications (SPI-B\&C) to support the UK government's response to Swine Flu.
} 
BIT was initially established within the UK Government's Cabinet Office (which supports the Prime Minister and, alongside the Treasury, is the corporate headquarters of the UK government), but is now a social purpose company that is jointly owned by the Cabinet Office, the innovation charity NESTA, and its own employees. While it is unclear precisely how BIT has informed COVID-19 policy, there appear to be at least three routes through which it can wield influence. The first is through its membership of the SPI-B and the SAGE advisory groups. The BIT's Chief Executive David Halpern sits on both SPI-B and SAGE, and there are two other BIT employees who participate in SPI-B. The second is directly through the Cabinet Office. Third is through the longer-term impacts which the BIT's understanding of human behaviour, and how best to influence it, has had on government policy over the last 10 years. While the precise power of this third form of influence is difficult to quantify, we claim it may be important in helping us understand the traction which the idea of behavioural fatigue was able to achieve.

\section{Behavioural fatigue: an intuitive, associative, yet ultimately orphan concept}

Given the role of the SPI-B Group and the long-standing influence of BIT at the very centre of government, it is clear that the behavioural sciences have been informing government responses to COVID-19. In oral evidence presented at the House of Lords Select Committee on Science and Technology on the $9^{\text {th }}$ June 2020, behavioural experts from SPI-B and BIT suggested that they provided advice on public communication and the likely compliance effects of messaging (placing particular emphasis on issues of consistency, clarity, and the use of trusted/relevant messengers) (House of Lords 2020). It was also stated that they advised on the results of ongoing surveys of public attitudes concerning various aspects of the COVID-19 crisis. While the influence of these groups on COVID-19 policy in the UK is difficult to determine precisely, what members of SPI-B and BIT seem to unequivocally agree upon is that they did not propose the notion of behavioural fatigue. Richard O'Brian, who is the head of communications at BIT told the British Medical Journal that

'The notion, idea, of 'behavioural fatigue' absolutely, categorically, did not come from us or anyone at BIT [...] We did not propose fatigue as grounds to delay or shorten social distancing or any other measures aimed at Covid-19. However the phrase entered the public or policy discourse, it was not from us.' (Mahase, 2020).

Writing in the same journal, Susan Michie and Robert West, both members of SPI-B, stated that 'the commonsense idea of 'behavioural fatigue' and concern that locking down too early 
may lead to widespread non-adherence later, was invoked in the UK for justification of the catastrophic delay of strict social distancing measures in the UK. Behavioural fatigue was an ill-defined new term that had no basis in behavioural science [...]' (Michie and West, 2020).

It does appear that behavioural scientists were asked to gather evidence and advise on the behavioural implications of quarantine measures (House of Lords, 2020). SAGE minutes from the $13^{\text {th }}$ March (that is 4 days after the Chief Medical Officer's public use of the term fatigue stated:

'There is some evidence that people find quarantining harder to comply with the longer it goes on. The evidence is not strong but the effect is intuitive. There is no comparable evidence for social distancing measures, but experience suggests it is harder to comply with a challenging behaviour over a long period than over a short period' (SAGE, 2020).

This statement would seem to contradict the suggestion that the behavioural scientists advising government were not endorsing some version of a behavioural fatigue hypothesis, even if not using that precise term. However, minutes of the same meeting also state:

'Difficulty maintaining behaviours should not be treated as a reason for not communicating with the public about the efficacy of the behaviours and should not be taken as a reason to delay implementation where that is indicated epidemiologically' (SAGE, 2020).

Although this statement is somewhat ambiguous, it suggests that on the $13^{\text {th }}$ of March (that is ten days before the UK's full lockdown came into force) behavioural scientists had found some evidence to support the idea that there could be a form of behavioural fatigue associated with long-term compliance with a national lockdown (in the more specific, but still relevant context of quarantine). But it was recommended that this evidence should not be used to delay the implementation of epidemiologically required measures. There are three citations that are noted on the SPI-B Evidence List that was published on $6^{\text {th }}$ March that may have offered evidence for behavioural fatigue (see Webster et al, 2020; Brooks et al, 2020; Brooks et al, 2020). All of these papers focus on questions associated with compliance with and the effects of quarantine measures, and two were still under review. While there are similarities between social lockdowns and quarantines, they are clearly not the same thing ${ }^{3}$. Ultimately, the behavioural

\footnotetext{
${ }^{3}$ Quarantine is associated with certain psychological/behavioural issues that we might expect during a lockdown (anger, infection fears, boredom, inadequate supplies, financial loss, and frustrations (see Brooks 2020). But are
} 
evidence that emerged from these sources emphasised the importance of limiting quarantine periods to a minimum to enhance compliance. While none of these papers refers to the notion of behavioural fatigue, the recommendations they make would obviously support core aspects of the theory. But the critical issue here is that these sources did not offer scientific evidence that is directly pertinent to the behavioural consequences of societal lockdowns. Furthermore, it appears that the evidence base of the $6^{\text {th }}$ March could not even countenance a phenomenon such as a total lockdown. In their "rapid review" of how to encourage behavioural compliance with quarantine, Webster et al state: '[A]s compulsory quarantine on any large scale is almost certainly not practicable in a democratic society, public health officials must do everything they can to encourage voluntary adherence to quarantine protocols' (2020: 167).

It is not unreasonable to speculate that, in the absence of direct behavioural evidence, SPI-B and then SAGE used insights into the deleterious consequences of quarantine, and associated forms of non-compliance, as a basis for indirectly endorsing the principles of behavioural fatigue, if not the theory itself. This form of expertise drift or transgressive competence is surely to be expected, and may well be necessary, in times of unprecedented crisis and uncertainty. It is our contention in this article, however, that transgressive competence needs to be interpreted in the particular institutional contexts within which it emerges.

To better understand how these transgressive competencies may have inadvertently enabled, if not directly supported, the concept of behavioural fatigue, it is important to have a clearer sense of what the term actually is. One of the reasons that behavioural fatigue was able to achieve some degree of policy influence is that it is an under-determined concept. According to Susan Michie (SPI-B member), behavioural fatigue is best thought of as a muddled concept, which covers aspects of loneliness, isolation, depression, and boredom which are associated with quarantine and lockdown (BBC, 2020). While a quintessentially fuzzy concept, there is still something quite behaviourally specific in the term. Unlike other notions of behavioural noncompliance (habituation, confirmation bias, hyperbolic discounting), it does not suggest immediate forms of behavioural resistance. Instead, behavioural fatigue intimates a gradual loss of capacity and a steady erosion of willpower to comply with a desired conduct. Interestingly, this vision of limited human willpower, resonates strongly with the insights that are associated with the more politically influential branches of the behavioural sciences in UK. Since its

also related to other effects that would be less common in a general social lockdown (for example, post-traumatic stress, social stigma, confusion (ibid)). 
inception, the BIT has brought renewed emphasis to the behavioural flaws that characterise the human condition, and how these can be addressed by well-designed policies (see Jones et al 2013). The scientific insights that the BIT have sought to bring to the policy-making process derive primarily from the interdisciplinary field of behavioural economics. According to behavioural economics, human behaviour is guided by two interconnected operating systems. System 1 is automatic, easily activated and often guided by emotions. System 2, on the other hand, is more laborious to maintain and is characterised by calculation and deliberation. Behavioural economics, and the behavioural insights it has promoted, argue that while policies have historically focused on System 2, that it is actually System 1 that has the more powerful influence on human behaviour.

System 1 policy thinking is helpful when it comes to addressing long-term policy problems such as climate change, investing in pension schemes, or organ donations, because these are things that naturally tend to be deferred and forgotten about. But, and this is critical, while behavioural economists emphasise System 1 approaches to policy problems, they do not suggests that humans cannot be very deliberative and rational in other circumstances. Indeed, work on the psychological impacts of disasters (such as earthquakes or floods) suggest that while System 1 behavioural responses can occur (often in the form of panic), it is more common for System 2 processes to produce rational and orderly processes of response (in the form of pro-social behaviours, collective action, and rule compliance) (evidence of System 2 responses appears to have informed Irish public policy much more than in the UK, resulting in an earlier lockdown in the Republic of Ireland (see BBC, 2020)). While this perspective may not explain where behavioural fatigue came from, it does provide one possible explanation as to why it appears to have been accepted as expert opinion (even in the absence of evidence). This indicates two main things about the role of the behavioural sciences in the UK response to COVID-19: 1. that in the absence of directly relevant scientific evidence the behavioural sciences were subject to forms of expertise drift as they advised UK politicians on areas where expertise was in short supply ${ }^{4} ; 2$. that, at least in case of concepts such as behavioural fatigue, processes of transgressive scientific competence may be enabled by established institutional norms. It may well be in this instance that in the absence of sound evidence an intuitive concept

\footnotetext{
${ }^{4}$ This situation was, of course, not unique to the behavioural sciences. The epidemiologist, John Ioannidis has argued that the Corona Virus crisis might be 'once-in-a-century evidence fiasco' (Ioannidis, 2020).
} 
was able to gain indirect scientific kudos from established behavioural assumptions about the human condition (Sibony, 2020).

\section{The authorization of behavioural fatigue in wider institutional context}

In some ways where the notion of behavioural fatigue came from, and how it was able to influence policy, are less significant than the question of why it was not questioned more (see Oliver, 2020). In the context of behavioural fatigue, it appears that certain views of the human condition (particularly its System 1 orientation) had established a consensus status at the heart of the UK government. In this context, Stephen Reicher, a social psychologist who sits on the SPI-B Group observed,

'[...] beneath all the confusions, there is an important point here. Is one view of human behaviour overly dominating in No.10 [the home of the UK Prime Minister] and has it led to bad decisions? Is there a need to broaden the input and give more weight to other views' (Tweet June $23^{\text {rd } 2020)}$

The implication here is that behavioural economics thinking may have had a disproportionate impact on government thinking about human behaviour through its connection with the BIT and the Cabinet Office. While SPI-B clearly embodies a much broader sweep of behavioural science expertise than BIT alone, it seems likely that SPI-B scientists, and the ways of thinking they advocated, where not close enough to decision-makers to effectively contest the notion of behavioural fatigue to which those decision-makers were intuitively sympathetic.

This perspective does raise other questions about the institutional structures associated with SAGE and SPI-B. In a recent interview, Professor Neil Fergusson (a key member of SAGE who was instrumental in recommending a social lockdown in the UK), provides important insights into the workings of the SAGE committee (Cowley, 2020). According to Fergusson, SAGE works on the basis that its experts do not, generally, come in direct contact with government Ministers. Rather scientific consensus (such that it is) is communicated from the Group to Ministers through the government's Chief Scientific Advisor and Chief Medical Officer. Fergusson compares this system of scientific advice to the situation in France during where experts had direct access to politicians. Insulating politicians from charismatic scientific advisors seems sensible, ensuring as it does that those advisors do not have undue influence on the policy-making process. However, in the context of a novel coronavirus, and untested plans to impose a social lockdown, it is evident that there was no clear consensus emerging from the 
behavioural sciences on the notion of behavioural fatigue or a delayed social lockdown ${ }^{5}$. The exposure of Minsters of State to alternative ways thinking at this point may have made it easier for them to dismiss the idea of behavioural fatigue as just one among many relevant concepts.

If the UK government's decision to delay social lockdown in March 2020 is a case of expertise drift in the behavioural sciences, it is not straightforward one. It appears likely that the notion of behavioural fatigue was an intuitive creation of a behavioural principle from outside of the behavioural sciences. Notwithstanding this, it is clearly a concept that resonates strongly with the core principles of a powerful behavioural science framework that had become influential within the British government. What is also clear, given that SPI-B argued that there was no directly relevant behavioural evidence to delay lockdown, and that nearly 600 behavioural scientists questioned the notion of behavioural fatigue, is that at least in the short term there was insufficient opportunity to contest the operational behavioural rationales of the UK state. What is also apparent is that the story of behavioural fatigue is a case of transgressive scientific competence, which necessitates a complex understanding of the nature of expertise drift in policymaking. In this case it is not just a question of behavioural scientists using their expert status to speculate on things that are beyond their epistemic range. Here the rise to prominence of a particular set of scientific perspectives on the human condition appears to have been facilitated by a set of institutional norms and organizational structures.

\section{BPP during COVID-19 in the Netherlands: the role of the Corona Behaviour Unit}

The focus of the analysis now shifts towards the role of behavioural insights within the Dutch COVID-19 response formulation. Similar to the UK case, within Dutch policymaking there has been a rapid and formalised take-up of behavioural expertise, most notably and visibly represented through the work of the Corona Behaviour Unit [in Dutch the Corona Gedragsunit, abbreviated CGU]. Tracing the activities and impacts of this particular unit during the early phases of the pandemic therefore offers a well-suited avenue for understanding the ways in which BPP expertise has shaped decision-making and how that process is shaped by existing institutional configurations.

Interestingly, as we will see below, following this particular institution reveals a picture of BPP's role that differs from the UK case. The Dutch case shows no obvious signs of expertise drift. The opposite - what could be called expertise 'thrift' - seemed to be the case in fact, with

\footnotetext{
${ }^{5}$ This is why on the $16^{\text {th }}$ March 2020 a group of nearly 600 behavioural scientists wrote an open letter to the UK government raising concerns about the notion of behavioural fatigue (Hahn et al 2020).
} 
experts being less extremist and exhaustive in the execution of their practice. It might even be argued that CGU breached with some of the iconic standards and norms within BPP. It is here that we see a potential expertise 'shift' of BPP under COVID-19. To understand these processed of 'thrift' and 'shift', in what follows we shed light on the developmental story of CGU and its (moderate) impacts on decision-making, and how this story fits within the wider Dutch institutional context and prehistory with BPP.

\section{CGU: broad influencer at the institutional edge}

The CGU was launched in April 2020 and designated to look at the unfolding crisis from a behavioural perspective, extract relevant insights from the existing behavioural science literature, monitor public health-related behaviours and opinions, and formulate advice about government communication. The unit is positioned within RIVM and ultimately responds to the director-general of the Ministry of Public Health and the Environment (VWS). It has been funded through a grant commissioned by the Dutch Research Council (NWO). The unit has a core team of five people, with a wider circle of about fifty people and an independent advisory council consisting of about fifteen professors with behavioural expertise ['Wetenschappelijke Adviesraad Corona Gedragsunit']. Since its launch, it has conducted various research projects including: literature studies; in-depth interviews; surveys; social media monitoring; ad hoc research; and research syntheses (RIVM 2020). Many of these policy outputs - next to information about the unit's members, goals, activities - are published on the unit's webpage. The motivation to start this unit, and the way the unit describes its own raison d'être in public media (e.g. Keulemans 2020), conforms to typical BPP discourse: to develop evidence-based policy it is of great importance to gain insight into the behaviours, drivers and needs of people. The more government policy and communication is attuned to those aspects, from a behavioural science perspective, the better the virus can be controlled. It is frequently mentioned that the essence of managing the pandemic at this point in time comes down to a matter of behaviour change, and that in the end it is 'our behaviour' that determines whether the spread of the virus is halted, meaning that behavioural expertise is in great demand (RIVM 2020).

Looking at how CGU was institutionally positioned and how it exercised influence over decision-making processes, we see clear differences with the UK case. In the public eye, BPP in the UK was represented by particular persons, with for instance David Halpern, CEO of BIT UK, being part of the UK's national crisis response team in multiple roles and thus easily able to feed decision-making with behavioural insights. In the Netherlands, BPP exercised influence 
in a less personificated manner. BPP seemed represented on the CGU mostly as a collective. There was no clear Dutch variant of a David Halpern figure. The Dutch crisis discourse did feature examples of experts that became key consulters to government and also 'public faces of science', most particularly director of RIVM's Centre for Infectious Disease Control Jaap van Dissel, but none of them were behavioural specialists. Admittedly, there have been incidental instances of behavioural specialists being consulted and taking part in top-level meetings. Before CGU's launch, the cabinet had ad hoc consultations with social psychology professor Reint Jan Renes, and later health psychology professor and CGU-member Marijn de Bruin attended a top-level meeting in het Catshuis. Next to this, in November 2020 professor Marijn de Bruin was asked to engage in discussion with parliament during an official technical briefing. But besides such incidental moments where behavioural specialists were at the heart of decision-making, most influence was exerted by the CGU unit operating at greater distance to decision-making. The CGU produced advice, syntheses and monitoring reports: policy outputs that in a less direct sense informed crisis management strategies.

CGU of course operated within a wider arena of COVID-19-related expert groups and government advisory committees, all differing in terms of closeness to decision-making. Within the zone of broad/indirect influence one might classify the activities of expert groups as the Red Team C19 NL, the SER Denktank Coronacrisis and the Tijdelijke Werkgroep Sociale Impact. Within the more influential zone of direct top-level consultation one would most notably find the Outbreak Management Team, and to a lesser extent the various formal planning agencies and advisory bodies (inter alia, CPB, CBS, WRR, DNG, PBS, SCP, ROB, RIVM). CGU seemed to operate mostly in the zone of broad/indirect influence. It had had no direct structural ties to top-level decision-making. Incidentally it was drawn into top-level decision-making but mostly it produced research findings and other outputs that would have to find their way to the top indirectly. Yet, the mere fact that a formal CGU was established to represent the behavioural science perspective, and given first signs that the unit's thinking has indeed shaped the government's response and communication (Issuemakers 2020), suggest that at the least it had some influence on decision-making. CGU was placed, so to say, 'at the institutional edge'.

The nature of the impact of CGU - and the field of behavioural science more generally - on Dutch policymaking is reflected in the Dutch public media and debate. While both the Dutch and the UK's case show an early-on publicity for behavioural expertise, in comparison to the fierce public debate and critical journalism in the UK (Sodha 2020; Ahmed 2020) the 
Netherlands has seen little discussion about the role of BPP. With regards to CGU, the media's interest has been limited to asking basic questions about what the unit is doing, who are in it, and what its policy advice entails (e.g. Van Kempen 2020; Keulemans; Issuemakers 2020). Unlike in the UK, no critical questions were asked about its legitimacy and influence. This public imago stands somewhat in contrast with a more generic media debate on the role of experts and expertise during COVID-19. In this debate, experts were attacked, challenged and blamed for giving faulty or one-sided advice, or entire knowledge disciplines were challenged on their value-add and relevance. Pleas were made to embed other perspectives - beyond the medical and virological confines - more strongly in decision-making (De Graaf 2020; Van Ostaijen 2020). While the debate about who should sit 'at the table' might indirectly challenge the semi-established role of BPP, this threat did not challenge its legitimacy directly. It was the more influential, non-behavioural scientific OMT that was subject to most critical scrutiny, for instance being accused of erroneous recommendations, lack of transparency and one-sidedness in its consultation (Nieuwsuur 2020).

What may also explain the moderate level of attention for CGU relates to the type of the ideas, observations and research results that the unit published. In the UK, behavioural expertise gained early prominence by means of very concrete ideas, with especially the behavioural science associated idea of 'behavioural fatigue' acting as a powerful motivator for an initial laissez-faire crisis response. The Dutch case shows no equivalent take-up of specific behavioural science (associated) theories as essential elements of the national crisis response. CGU delivered many relevant bits of information through its research and monitoring endeavours, but not crucial bits. Dutch BPP seemed to be represented by CGU more as a generic set of ideas, methods and goals rather than as, more narrowly, one particular concept or theory or strategy that was crucial to controlling the pandemic. Or, at the least, in the open political and public debate, BPP did not get publicity through specific theoretical insights.

Admittedly, there is a striking similarity between the Dutch and UK case when it comes to contested notion of 'herd immunity' - indeed a highly specific notion that also popped up in the Dutch crisis discourse. On the $16^{\text {th }}$ of March, premier Mark Rutte gave a television address in which he introduced this notion, stating the following:

'The reality is also that in the coming period a large proportion of the Dutch population will become infected with this virus. That's what the experts are telling us now. They 
are also telling us that - as we wait for a vaccine or treatment to be developed - we can delay the spread of the virus and at the same time build up population immunity in a controlled manner.' (Rijksoverheid 2020)

That same evening, Jaap van Dissel, chair of the OMT, spoke along similar lines. This soon produced public confusion, with some interpreting the Dutch crisis response as actively aiming for long term herd immunity instead of immediately curtailing the virus. On the $18^{\text {th }}$ of March, both Mark Rutte and Jaap van Dissel reframed their position, this time stating explicitly that herd immunity was not an active goal. This case parallels BIT UK CEO David Halpern's plea for building herd immunity in the UK, for which he was widely blamed as soon as it became clear that such a strategy would come with disastrous health consequences. The notable difference, however, is that in the Netherlands it was not behavioural experts representing behavioural science introducing this idea and taking the heat for it but others. BPP had no role in this public contestation.

Beyond its institutional positioning and media attention, in understanding CGU's impacts it is also telling to look at the type of tasks conducted by experts from CGU. BPP has typically been described as an interventionist field, aiming to produce concrete and direct behaviour change strategies, comparable to Salamon's (2002) notion effecting policy instruments. CGU's practice however seemed less geared towards building interventions and more towards gathering and analysing information, which ties better with Salamon's notion of the detecting mode of policy instrumentation. The unit's detector role clearly reflects in the projects it has undertaken, e.g. synthesizing literature, monitoring social media, and conducting surveys and in-depth interviews (RIVM 2020). It is also telling that the RIVM webpage where the official information about CGU can be found is headed with the text 'Behavioural Science Research on COVID-19' [italics added], emphasizing the more exploratory, monitoring and noninterventionist nature of the unit.

Admittedly, an aspect of CGU's task package that fell more in the effecting realm was its consultation regarding the government's crisis communication. Thus far, CGU has given direct ad hoc advice, it has conducted literature reviews of effective communication strategies (e.g. regarding handwashing) (CGU 2020a) and developed a step-by-step action plan of behaviourally-informed crisis communication (CGU 2020b). Yet, as already stated, CGU's effecting ambitions seem far outweighed by its monitoring activities. Most projects and related 
reports were concerned with detector-related inquiries about how people are responding to crisis measures, what they are saying on social media, and how it is affecting their daily social lives - all without the explicit drive to follow-up with behaviour change interventions.

In short, while in the UK BPP was in a leading role pushed by relatively influential behavioural specialists and very concrete behavioural science (associated) insights, in the Netherlands BPP appeared to play an at most semi-influential role. The key player herein was a dedicated policy unit with moderate access to top-level decision-making. It would seem that CGU delivered a wealth of insights and recommendations but not crucial bits of information regarding key decisions (e.g. on whether and when to go in lockdown). The unit's value-add was mostly restricted to synthesizing existing research and tracing current behaviours and opinions within society so as to get a sense of how effective measures are and how people are affected by them. CGU's application of behavioural science appeared to stay well within the epistemic bounds of BPP.

\section{The 'epistemic modesty' of CGU in wider institutional context}

To better understand the seeming absence of processes of expertise drift within the Dutch BPP scene during COVID-19, we now want to look at the wider institutional context in which BPP has operated. Roughly speaking, Dutch BPP has started to fully flourish a few years later after it emerged in the Anglosphere. Dutch BPP has been very much influenced by the BPP as pioneered in the UK and the USA, which reflects in the inheritance of many practices, beliefs and rhetoric (Feitsma 2019). Compared to the centralised uptake in the UK, behavioural science has had a 'slower landing' within the Dutch policy scene. The Dutch BPP field is still in the process of institutionalization and is doing so in a more fragmented style, with various agencies autonomously experimenting with ways to embed behavioural science in their work processes. It is quite plausible that this experimental and exploratory phase has had significant implications for how behavioural expertise has been used, and whether it was possible to use this body of knowledge to its fullest potential. Being still 'new kids on the block' may have facilitated processes of what we would call expertise 'thrift', i.e. a more modest/minimal use of expertise, as the perceived authorization for a more exhaustive use was still lacking and as other knowledge perspectives might prevail in the current institutional environment.

The particular institutional prehistory with BPP might also explain part of the relatively 'calm water' in which Dutch BPP found itself when compared to the fierce media debate about BPP's 
contributions in the UK. How did it come that in the UK the role of behavioural science got so much more politicised? It is important to note that the UK government has had stronger ties to behavioural science, and that the UK also has had a longer history of critical journalism on BPP (e.g. Dunt 2014). The rapid politicization of behavioural insights during COVID-19 in the UK in this sense can be seen as a continuation of an already existing institutional dynamic. Vice versa, BPP has had a more careful and fragmented institutionalization in the Netherlands, and has been much less object of public and political debate. COVID-19 has not significantly changed this (despite more interest in the role of behavioural science in the pandemic state). This 'calm water' may have prevented unintentional processes of expertise drift, like in the UK, where behavioural science gets misinterpreted and misused within public and political debate without experts being able to counter it.

The existing prehistories with BPP might also explain the diverging expertise dynamics between the UK and the Netherlands regarding the particular contestations around the notion of 'herd immunity'. In the UK, it was David Halpern who was one of the first SAGE-advisers to publicly hint at an active herd immunity strategy. This seems partly why he was held to account for this statement, not because he was a behavioural scientist per se. Indeed, the notion of herd immunity has no direct behavioural science ties but comes from bacteriology and is common parlance in public health science. Yet, David Halpern's insinuation was easily linked in the public debate to his role as a thought leader within BPP, and so via Halpern's persona 'herd immunity' also got associated with BPP. In the Netherlands, those who coined the term had no behavioural background, nor did there exist a powerful institutional bedding that could lead to a situation in which the term was associated with BPP. Hence, 'herd immunity' never got a behavioural science association in the Dutch debate. The notion of 'behavioural fatigue' raises another interesting question as to why (at least in the UK's) public perception this notion got connected to BPP, despite its non-existence in the behavioural science literature. Is there a particular 'magnetic' or 'contagious' quality to the ideational content of BPP? Again, the UK's prehistory with BPP might be a factor of influence, meaning that the relatively high levels of influence and prominence of BPP within the UK might increase the side risk of indirectly endorsing vague and non-scientific concepts. The more mainstream behavioural science gets, the more susceptible it might become to misassociation, misattribution, or other processes of expertise drift. 


\section{Discussion: Diverging knowledge dynamics for BPP under COVID-19}

\section{Refining and enriching the vocabulary on expertise drift}

Our empirical account of BPP during COVID-19 urges to rethink, or at the least refine, the idea of 'expertise drift'. The UK case on behavioural fatigue has made clear that it is important to understand expertise drift as a context dependent phenomenon. Expertise drift can be the process of a chaotic dynamic in which multiple institutional processes interrelate with each other. How expertise comes to drift out of its epistemic range is not per se an intentional process, and the immediate cause does not necessarily lie within the scientific domain, i.e. with the statements and acts of individual academic experts. The UK case shows that even when the behavioural science community eventually explicitly distanced itself from the notion of behavioural fatigue, the UK government's established ties with BPP thinking still generated a form of institutional seeding through which that notion could gain prominence. When considering the expertise drift that emerged here it is hard to 'point fingers' at specific institutions or players: it makes much more sense to take into account the wider institutional picture that has enabled such processes to occur.

Besides refinement, we also call for enrichment of the vocabulary on expertise drift. Looking at the Dutch case and the CGU's distinct task package, we are led not in the direction of expertise 'drift' but rather in that of a 'thrifty' adoption of behavioural expertise. CGU's approach towards BPP had a certain 'modesty' to it, being positioned 'at the institutional edge', and confining its activities to synthesizing literature and monitoring societal behaviours. This 'thriftier' approach towards utilizing behavioural expertise was perhaps to expected when situated in its wider institutional context: compared to the UK, Dutch BPP has had a 'slower landing' and has been institutionalised in more fragmented, pragmatic and pluralistic ways. It has not (yet) had the level of take-up and influence like BPP in the UK, arguably diminishing the chances for processes of expertise drift to occur.

The Dutch case might however also be interpreted as a case of behavioural expertise 'shift'. The 'shifty' nature of CGU's adoption of BPP could be inferred from the observation that core aspects of standard BPP practice and norms - including the resolute intention to build interventions and change and not merely monitor behaviours - were fairly absent in CGU's work methods. It might be that under COVID-19 Dutch BPP has been reinterpreted and reshaped in line with what was at the time thought to be needed, feasible and legitimate. Such 
a 'shift' is in line with previous observations of the rather fluid boundaries of BPP practice (Ball \& Feitsma 2019). It also suggests that during this COVID-19 crisis, behavioural experts are finding ways to adapt and tailor their approach to their local environments as needed.

Table 1 gives an overview of the diverging dynamics of expertise that we have observed in the UK and the Netherlands. It also describes the opportunities and risks that come with these dynamics, and the institutional contexts that might facilitate these dynamics to occur.

\section{Table 1. Dynamics of expertise within BPP}

Dynamic of Description Opportunities Risks Institutional prevalence
expertise

\begin{tabular}{lllll}
\hline Behavioural & Expertise is applied & Impulse towards & Mis- and & Likelier in BPP hotspots, \\
expertise drift & beyond the epistemic & deeper and broader & overapplication & where institutional structures \\
& bounds and & institutionalization & leading to ill- & favour certain behavioural \\
explanatory limits of & of BPP and more & informed & insights and downplay \\
BPP. & interdisciplinarity & decisions & diversity of thinking.
\end{tabular}

\begin{tabular}{lllll}
\hline Behavioural & Expertise is applied & BPP expertise can & The potential of & Likelier in open and \\
expertise & in a non-exhaustive & be balanced out & BPP is realised & fragmented institutional \\
thrift & fashion, while still & with other forms of & only minimally. & structures, where diverse and \\
& conforming to & expertise. Room for & & crowded epistemic arenas \\
& standard norms & a tailored approach. & prevent a full roll-out of BPP. \\
& within BPP. & & &
\end{tabular}

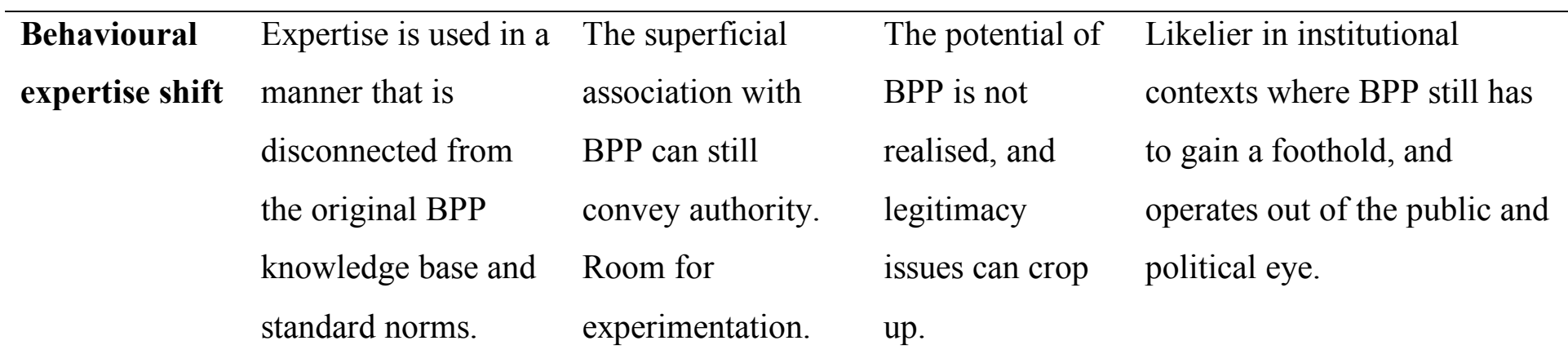




\section{Building expertise-savvy institutions}

Having pinpointed these diverse dynamics of expertise during COVID-19, we can follow-up by asking which type of dynamics would be most helpful for policymaking. We might also ask how we could build institutions that facilitate the 'good' uses of expertise. Although prima facie expertise drift and shift would obviously seem damaging dynamics and expertise thrift a desirable one, we think the assessment hereof is more problematic. That is, all three types of dynamics could be said to have their own advantages and disadvantages, risks and opportunities - as captured in Table 1 above. While expertise drift might indeed lead to bad if not catastrophic (certainly in the context of COVID-19 where science cannot only save but also cost lives) policy decisions, at the same time it can generate powerful benefits or side-effects, particularly by stimulating multi- and interdisciplinarity as knowledge 'transgresses', moving from one disciplinary domain into another. While expertise thrift might prevent experts from overpromising and overreaching, it may also obstruct and curtail the flow of knowledge which in turn may lead to poor decisions. And while expertise shift might imply a corrupted use of knowledge which does not respect the original epistemic boundaries, it may also have the beneficial side-effect of stimulating a healthy degree of experimentation within a field that is still 'under construction' anyway.

In other words, assessing how desirable these diverging dynamics of expertise respectively are, and recommending how we should rebuild institutional configurations accordingly, is tricky not in the least because of the fundamentally political nature of expertise (Strassheim 2017). When we zoom out and consider the wider 'politics of expertise' taking place in contemporary policymaking, we must acknowledge that there are no objective scientific answers to normatively laden questions as to which bodies of knowledge would deserve more influence (and thus might be more allowed in the direction of 'drifting') and which less (and thus would require a 'thriftier' take-up). What scholars within the policy sciences can do is speak truth to power by continuously unpacking how and why expertise actually gets employed - for either instrumental or political purposes - so that at the least policy decisions can be made from a conscious understanding of how knowledge functions within power-infused policy processes. 


\section{References}

Abbasi, K. (2020). Behavioural fatigue: a flawed idea central to a flawed pandemic response. British Medical Journal.

Ahmed, N. (2020, March 23). Behavioural Scientists told Government to use 'Herd Immunity' to Justify Business-As-Usual. Byline Times. Retrieved from https://bylinetimes.com/2020/03/23/covid-19-special-investigation-part-three-behaviouralscientists-told-government-to-use-herd-immunity-to-justify-business-as-usual/

Ball, S. \& Feitsma, J.N.P. (2019). The boundaries of Behavioural Insights - Observations from two ethnographic studies. Evidence \& Policy.

BBC (2020, 26 June) 'Behavioural science and the pandemic' BBC Radio 4 Documentary. Retrieved from https://www.bbc.co.uk/programmes/m0001207

Coulson, A. and Fararrio, C. (2007) 'Institutional Thickness': Local Governance and Economic Development in Birmingham, England' International Journal of Urban and Regional Research 31: 591-615.

Hahn, U., Chater, N., Lagnado, D., Osman, M. \& Raihini, N. (2020, March 16). Why a Group of Behavioural Scientists Penned an Open Letter to the U.K. Government Questioning Its Coronavirus Response. Behavioral Scientist. Retrieved from https://behavioralscientist.org/why-a-group-of-behavioural-scientists-penned-an-open-letterto-the-uk-government-questioning-its-coronavirus-response-covid-19-social-distancing/

Brooks, S.K, Smith, L.E, Webster, R.K, Weston, D., Woodland, L., Hall, I., Rubin, G.J. (2020). The impact of unplanned school closure on children's social contact: Rapid evidence review. Eurosurveillance (under review)

Brooks, S.K., Webster R.K., Smith L.E., Woodland, L., Wessely, S., Greenberg, N., Rubin, G.J. (2020). The psychological impact of quarantine and how to reduce it: Rapid review of the evidence. Lancet, https://doi.org/10.1016/S0140-6736(20)30460-8 
Capano, G., Howlett, M., Jarvis, D. S., Ramesh, M., \& Goyal, N. (2020). Mobilizing policy (in) capacity to fight COVID-19: Understanding variations in state responses. Policy and Society, 39(3), 285-308.

Cowley, J. (2020, July 31). Neil Ferguson: The Covid modeller. NewStatesman. Retrieved from https://www.newstatesman.com/science-tech/coronavirus/2020/07/neil-ferguson-covidmodeller

Corona Gedragsunit (2020a). Basisdocument preventiegedrag en welzijn. Retrieved from https://www.rivm.nl/documenten/basisdocument-preventiegedrag-welzijn

Corona Gedragsunit (2020b). Stappenplan overheidscommunicatie en interventies. Retrieved from https://www.rivm.nl/documenten/stappenplan-overheidscommunicatie-interventies

Christensen, J. (2018). Economic knowledge and the scientization of policy advice. Policy sciences, 51(3), 291-311

Collins, H., \& Evans, R. (2008) Rethinking Expertise. University of Chicago Press: Chicago.

De Graaf, Jensen, L, Santing, C., \& Knoeff, R. (2020, May 1). Historici moeten ook meedenken juist nu. NRC. Retrieved from https://www.nrc.nl/nieuws/2020/05/01/historicimoeten-ook-meedenken-juist-nu-a3998484

Dunt, I. (2014, Feb 5). Nudge nudge, say no more. Brits' minds will be controlled without us knowing it. The Guardian. Retrieved from https://www.theguardian.com/commentisfree/2014/feb/05/nudge-say-no-more-behaviouralinsights-team

Epstein, S. (1996). Impure Science: AIDS, Activism, and the Politics of Knowledge. University of California Press: Berkeley, California.

Esmark, A. (2020). The New Technocracy. Bristol University Press: Bristol.

Ewert, B. (2020). Moving beyond the obsession with nudging individual behaviour: Towards a broader understanding of Behavioural Public Policy. Public Policy and Administration, 35(3), 337-360.

Feitsma, J.N.P. (2020). Inside the Behavioural State. Eleven Publishing: The Hague. 
Feitsma, J.N.P. (2020). Crisiskabinet Rutte-III en de stille terugtocht naar het oude normaal. Tijdschrift voor Sociale Vraagstukken, 2, 8-11.

Feitsma, J.N.P. \& Whitehead, M. (2019). Bounded Interdisciplinarity: Critical Interdisciplinary Perspectives on Context and Evidence in Behavioural Public Policies. Behavioral Public Policy

Fischer, F. (2009). Democracy and Expertise: Reorienting Policy Inquiry. Oxford University Press: Oxford.

Fischer, F. (1990). Technocracy and the Politics of Expertise. SAGE Publications.

Flinders, M., \& Buller, J. (2006). Depoliticisation: Principles, tactics and tools. British Politics, 1(3), 293-318.

Halpern, D. (2015). Inside the Nudge Unit. London: Ebury Publishing.

Holst, C. (2012). What is epistocracy?. In Sacred Science? Wageningen Academic Publishers: Wageningen.

House of Lords (2020, June 9). Corrected oral evidence: The science of Covid-19. Select Committee on Science and Technology. Retrieved from https://committees.parliament.uk/oralevidence/488/html/

Issuemakers (2020). Interview Reint Jan Renes Gedragswetenschap en de Corona Gedragsunit. Retrieved from https://www.issuemakers.nl/blog/reint-jan-renes-overgedragswetenschap-en-de-corona-gedragsunit-het-moment-dat-van-dissel-onzestudieresultaten-mee-ging-nemen-in-zijn-verhaal-was-voor-ons-een-klein-succes-momentje

Jasanoff, S. (ed.) (2004). States of Knowledge: The Co-Production of Science and the Social Order. Routledge: London.

John, P. (2018). How far to nudge? Cheltenham: Edward Elgar Publishing. 
Jones, R., J. Pykett, \& Whitehead, M. (2013). Changing Behaviours: On the Rise of the Psychological State. Cheltenham/Northampton: Edward Elgar Publishing.

Leggett, W. (2014). The Politics of Behaviour Change: Nudge, Neoliberalism and the State. Policy and Politics, 42(1): 3-19.

Lunn, P. D., Belton, C. A., Lavin, C., McGowan, F. P., Timmons, S., \& Robertson, D. A. (2020). Using Behavioral Science to help fight the Coronavirus. Journal of Behavioral Public Administration, 3(1).

Keulemans, M. (2020, July 10). RIVM: 'Drie keer zoenen? Die gewoonte gaan we niet meer terugzien'. De Volkskrant. Retrieved from https://www.volkskrant.nl/wetenschap/rivm-driekeer-zoenen-die-gewoonte-gaan-we-niet-meer-terugzien b1af0305/

Mahase, E. (2020). Covid-19: Was the decision to delay the UK's lockdown over fears of "behavioural fatigue" based on evidence? British Medical Journal.

McIntyre, L. (2018). Post-truth. MIT Press: Cambridge.

Michie, S. \& West, R. (2020). Behavioural, environmental, social, and systems interventions against covid-19. British Medical Journal.

Mulderrig, J. (2018). Multimodal strategies of emotional governance: a critical analysis of 'nudge' tactics in health policy. Critical Discourse Studies, 15(1): 39-67.

Nieuwsuur (2020, April 25) Oud-directeur RIVM: 'Advies van OMT aan het kabinet is te eenzijdig'. Retrieved from https://nos.nl/nieuwsuur/artikel/2331752-oud-directeur-rivmadvies-van-omt-aan-het-kabinet-is-te-eenzijdig.html

Nowotny, H. (2000). Transgressive competence: The narrative of expertise. European Journal of Social Theory, 3(1), 5-21.

Oliver, A. (2020). Finding the trees in the wood: behavioural science and the UK's response to COVID-19. British Politics and Policy at LSE. 
Pierre, J. (2020). Nudges against pandemics: Sweden's COVID-19 containment strategy in perspective. Policy and Society, 39(3), 478-493.

Rijksoverheid (2020, March 16). TV-toespraak van minister-president Mark Rutte. Retrieved from https://www.rijksoverheid.nl/documenten/toespraken/2020/03/16/tv-toespraak-vanminister-president-mark-rutte

RIVM (2020). Gedragswetenschappelijk onderzoek COVID-19. Retrieved from https://www.rivm.nl/gedragsonderzoek

SAGE (2020). SAGE 15 minutes: Coronavirus (COVID-19) response, 13 March 2020. Retrieved from https://www.gov.uk/government/publications/sage-minutes-coronaviruscovid-19-response-13-march-2020

Salamon, L. M. (2002). Introduction: New Governance, New Instruments. Handbook of Policy Instruments.

Saretzki, T. (2015). Habermas, critical theory and public policy. In Handbook of critical policy studies. Edward Elgar Publishing.

SPI-B (2020) 'Independent Scientific Pandemic Insights Group on Behaviours (SPI-B)'. Retrieved from https://www.gov.uk/government/groups/independent-scientific-pandemicinfluenza-group-on-behaviours-spi-b

Sibony, A. L. (2020). The UK COVID-19 Response: A Behavioural Irony? European Journal of Risk Regulation, 1-8.

Sodha, S. (2020, April 26). Nudge theory is a poor substitute for hard science in matters of life or death. The Guardian. Retrieved from https://www.theguardian.com/commentisfree/2020/apr/26/nudge-theory-is-a-poor-substitutefor-science-in-matters-of-life-or-death-coronavirus 
Strassheim, H. (2017). Bringing the Political Back in: Reconstructing the Debate over

Evidence-Based Policy. A Response to Newman. Critical Policy Studies, 11(2): 235-245.

Strassheim, H., \& Beck, S. (Eds.). (2019). Handbook of Behavioural Change and Public Policy. Edward Elgar Publishing

Van Kempen, J. (2020, April 29). Psychologen adviseren hoe de slimme lockdown draaglijk blijft. Het Parool. Retrieved from https://www.parool.nl/nieuws/psychologen-adviseren-hoede-slimme-lockdown-draaglijk-blijft b41e7ab1/

Van Ostaijen, M. (2020, October 21). Het Outbreak Management Team heeft een socioloog nodig. NRC. Retrieved from https://www.nrc.nl/nieuws/2020/10/21/tijd-om-een-socioloog-inhet-omt-te-benoemen-a4016776

Webster, R.K., Brooks, S.K., Smith, L.E., Woodland, L., Wessely, S., Rubin, G.J. (2020). How to improve adherence with quarantine: Rapid review of the evidence. Public Health (under review).

Wesselink, A., Buchanan, K. S., Georgiadou, Y., \& Turnhout, E. (2013). Technical knowledge, discursive spaces and politics at the science-policy interface. Environmental Science \& Policy, 30, 1-9.

Whitehead, M., Jones, R., Lilley, R., Pykett, J. \& Howell, R. (2017). Neuroliberalism. Behavioural Government in the Twenty-First Century. Abingdon/New York: Routledge.

Whitehead, M., Jones, R., Howell, R., Pykett, J. \& Lilley, R. (2018). Neuroliberalism: Cognition, Context and the Geographical Bounding of Rationality. Progress in Human Geography, advance online publication. doi: 10.1177/0309132518777624

Whitehead, M. (2020). Surveillance Capitalism in the Time of Covid-19. ISRF. Retrieved from https://www.isrf.org/2020/05/11/surveillance-capitalism-in-the-time-of-covid-19-thepossible-costs-of-technological-liberation-from-lockdown/ 